\title{
Dependence of Lattice Distortion and Dielectric Response of Zinc Aluminate on Milling Frequency
}

\author{
HADIA Noor ${ }^{a^{*}}$, SAIRA Riaz ${ }^{b}$, MALIK Maryyam Iram ${ }^{c}$, \\ AMNA Siddiqi ${ }^{d}$ and SHAHZAD Naseem ${ }^{\mathrm{e}}$
}

\author{
Centre of Excellence in Solid State Physics, University of Punjab, Lahore 54590, Pakistan \\ a*hadia.cssp@pu.edu.pk, ${ }^{\mathrm{b}}$ saira.cssp@yahoo.com, ${ }^{\mathrm{c}}$ merium_iram@hotmail.com, \\ asiddiqi93@yahoo.co.uk, ${ }^{\text {e }}$ shahzad_naseem@yahoo.com
}

\begin{abstract}
Keywords: $\mathrm{ZnAl}_{2} \mathrm{O}_{4}$, Milling Frequency, XRD, Grain Size, Dielectric Constant, Polarization.
\end{abstract}
\begin{abstract}
Zinc aluminate $\left(\mathrm{ZnAl}_{2} \mathrm{O}_{4}\right)$ samples were prepared using nano-milling based solid state reaction method for several potential applications. Effect of milling frequency on structural and dielectric behavior of $\mathrm{ZnAl}_{2} \mathrm{O}_{4}$ has been explored systematically. Investigation of crystal structure reveals that change in lattice parameter by milling does not alter the cubic lattice of $\mathrm{ZnAl}_{2} \mathrm{O}_{4}$. This milling frequency at the nano size resulted in a gradual decrease in the particle size, which can be attributed to the inhomogeneous defects. Grain size in nanometers has been calculated by XRD using Debye-Scherrer formula. Dielectric measurements performed in the range of $20 \mathrm{~Hz}-20 \mathrm{MHz}$ confirms the Maxwell -Wagner two-layer model which is consistent with the Koop's theory. High value of ac conductivity indicates that milling blocked the ionic transport. As a result of Nyquist plots, a single semicircle was obtained which indicated the leading role of grain (bulk). The variation in the semicircle radii for different samples is due to the influence of milling frequency.
\end{abstract}

\section{Introduction}

In the ceramics, spinal family is an ideal material to form the ternary oxides because of its significant electrical, mechanical, magnetic and optical properties. The common chemical formula of spinal structure oxides is $\mathrm{AB}_{2} \mathrm{O}_{4}$. The compounds which possess spinal structure are capable to host extensively divalent, trivalent, and tetravalent cations. It is observed that such kind of compounds have wide band gaps which make these compounds attractive for photoelectronic and optical applications [1]. High melting temperature, high strength, and high resistance to chemical attack are exceptional properties of these compounds. Among the spinal family compounds, zinc aluminate $\left(\mathrm{ZnAl}_{2} \mathrm{O}_{4}\right)$ has motivated attention because of its unique properties such as high thermal and chemical stability, low acidity, a hydrophobic nature high mechanical resistance and high quantum yields [2-5]. Therefore, it can be used as a catalyst for the fabrication of polymethylbenzenes, preparation of styrene initiation from acetophenons, double bond isomerisation of alkenes, dehydration of saturated alcohols to olefins, methanol and higher alcohol preparation $[6,7]$. The wear resistance and mechanical properties of white ceramic tiles can be enhanced by introducing $\mathrm{ZnAl}_{2} \mathrm{O}_{4}$ as a second level in glaze sheets [8]. Furthermore, $\mathrm{ZnAl}_{2} \mathrm{O}_{4}$ is appropriate for UV optoelectronic application because it is transparent beyond $320 \mathrm{~nm}$ wavelength [9]. It is necessary to consider the microstructure of material to achieve the desired targets/objects because electrical, mechanical, magnetic and optical properties are determined by particle size.

Several methods such as solid state reaction [10-12], co-precipitation [13, 14], sol-gel [15, 16] and hydrothermal $[17,18]$ have been employed to prepare $\mathrm{ZnAl}_{2} \mathrm{O}_{4}$ powders. Every method has some merits and demerits. However, milling based solid state reaction is an easy way to prepare composites material due to its specific features such as low cost, small energy consumption and time saving. In milling process, milling balls rotating with high speed in closed vessel create variation in the material properties. Hard materials like steel and tungsten carbide are used to fabricate the milling balls. Milling balls crush the materials into small size from millimeter to nanometers. The crystal defects such as dislocation density, vacancies, deformation network are induced by milling. The quantity of interfaces increases and particle size reduces in the range of 
nanometers due to the fracturing process [19]. Milling frequency and time are important parameters of the milling materials. The required energy and concentration of the milling materials are directly related to these parameters. In the present study, $\mathrm{ZnAl}_{2} \mathrm{O}_{4}$ samples were prepared by nano-milling based solid state reaction method. Effect of milling frequency on the crystal structure and the dielectric properties of $\mathrm{ZnAl}_{2} \mathrm{O}_{4}$ specimens were explored.

\section{Experimental Details}

Zinc aluminate was prepared by solid state reaction. Mixture of $\mathrm{ZnO}$ (99.99\% pure) and $\mathrm{Al}_{2} \mathrm{O}_{3}$ $(99.99 \%)$ was prepared at room temperature. The following reaction is straightforward to attain $\mathrm{AB}_{2} \mathrm{O}_{4}$ type compounds.

$$
\mathrm{ZnO}+\mathrm{Al}_{2} \mathrm{O}_{3} \rightarrow \mathrm{ZnAl}_{2} \mathrm{O}_{4} \text {. }
$$

Five balls at frequency of $20 \mathrm{~Hz}$ ground the mixture in the ceramic container for two hours. After milling, pellet was formed by hydraulic press. $27.58 \mathrm{MPa}$ pressure was applied for 2 minutes to prepare pellet. The milling frequency, area and thickness of pellets are given in Table 1. After this, all samples were heated at $1000{ }^{\circ} \mathrm{C}$ in oxidizing environment for two hours. The prepared samples were characterized by X-Ray Diffraction (Bruker D8) and impedance analyzer (Wayne Kerr $6500 \mathrm{~B})$ to determine the crystal structure and frequency dependent dielectric parameters, respectively.

Table 1. Details of the samples prepared by nano-milling.

\begin{tabular}{|c|c|c|c|}
\hline Sample ID & Milling frequency [Hz] & Thickness [cm] & Area $\left[\mathbf{c m}^{\mathbf{2}}\right]$ \\
\hline A & 0 & 0.05 & 0.82 \\
\hline B & 20 & 0.13 & 0.90 \\
\hline C & 25 & 0.12 & 0.92 \\
\hline D & 30 & 0.21 & 0.89 \\
\hline E & 35 & 0.12 & 0.99 \\
\hline F & 40 & 0.12 & 0.88 \\
\hline
\end{tabular}

\section{Results and Discussion}

Fig. 1 shows the x-ray diffraction patterns of samples A-F. The diffraction peaks corresponding to (220), (311), (422), (511) and (440) indices reveal the cubic structure of $\mathrm{ZnAl}_{2} \mathrm{O}_{4}$ as reported in previous studies $[20,21]$. The presence of shoulder peaks located at $31.65^{\circ}$ and $36.55^{\circ}$ in unmilled sample (A) indicates that reactants are not completely incorporated with each other without milling because $\mathrm{ZnAl}_{2} \mathrm{O}_{4}$ as well as $\mathrm{ZnO}$ and $\mathrm{Al}_{2} \mathrm{O}_{3}$ have characteristic peaks at the same level of $2 \theta$ [22, 23].

The plots of crystallite size and dislocation density as a function of milling frequency are illustrated in Fig. 2. Variation of crystallite size from 23 to $31 \mathrm{~nm}$ was observed with increase in milling frequency from 0 to $40 \mathrm{~Hz}$. The values of crystallite size decreased with increase in dislocation density [24]. This observation clearly points out the relationship between crystallite size and dislocation density because of substitution of various anion and/or cation by milling. During milling, the crystallite size depends upon the induction of defects. Therefore, inhomogeneous defects are produced that change the crystallite size. In addition, neighboring grains have different energies and these neighboring grains define the grain size. It is possibility that milling induces such defects in polycrystalline material by continuous crushing which break up the crystals into small crystallites thus going towards nano size. In the beginning, lattice deformation due to milling is tolerable then continuous milling produced plastic deformation in the lattice. As a result of it, surface diffusion barrier and grain boundary diffusion energy increased which produced delay in grain boundary diffusion. Therefore, crystallite size reduced at high milling frequency. 


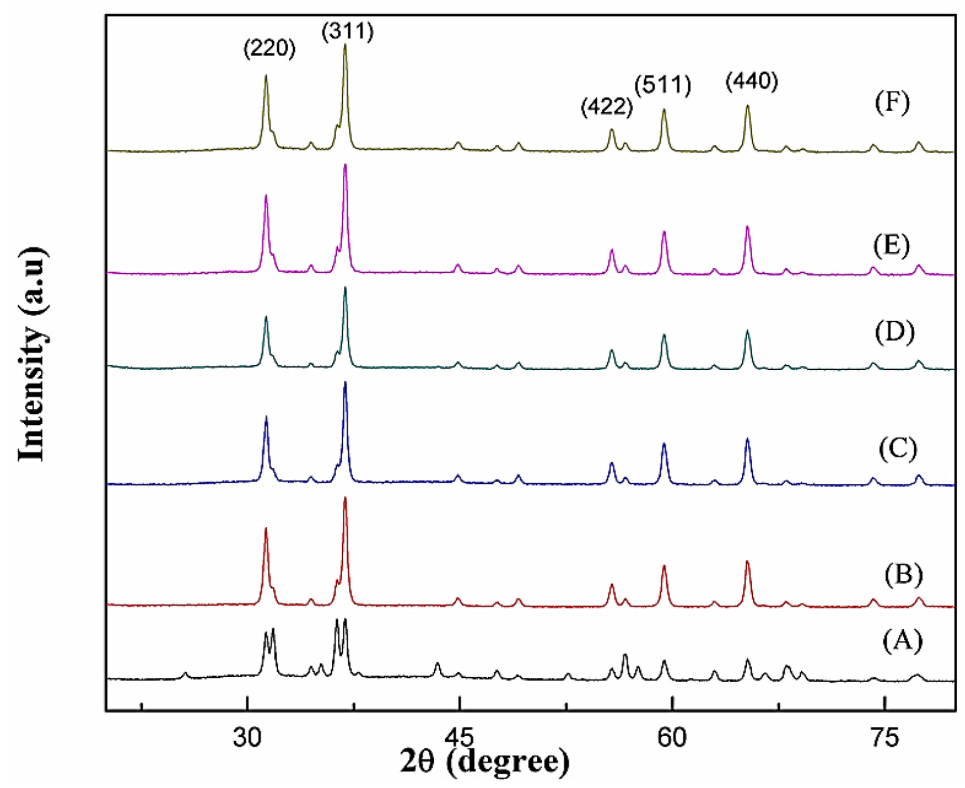

Fig. 1. Indexed XRD patterns of samples A-F.

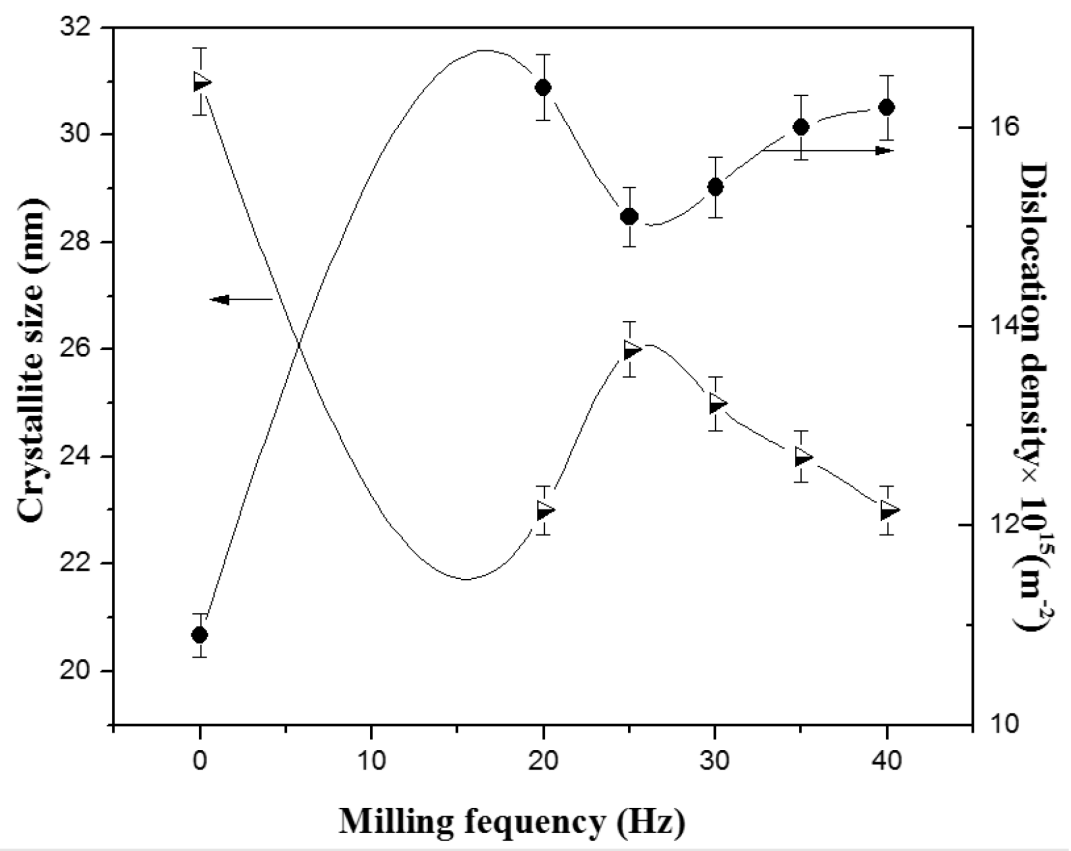

Fig. 2. Crystallite size and dislocation density as a function of milling frequency.

Frequency dependent dielectric constant of samples A-F are displayed in Fig. 3. Dielectric constant decreases with increase in frequency and becomes almost constant at high frequency. It is clear that dispersion behavior is independent of applied field at higher frequency. Several research groups $[21,25,26]$ have reported same results in ceramic materials. Such a dielectric dispersion trend can be explained on the basis of Maxwell Wagner polarization theory [27]. According to it, two layers of grains and grain boundary form an inhomogeneous dielectric specimen. Grain boundaries have low conductivity whereas the grains are more conductive. Initially at low frequency region, resistive grain boundaries play a leading role as compared to polarization in describing the dielectric properties. Space charge carriers associated with dielectric specimen need finite time to align their axes according to the alternating electric field resulting in decreased dielectric constant at high frequency. It was found that sample D milled at $30 \mathrm{~Hz}$ possessed high dielectric constant values as shown in Fig 4. Initially dielectric value increases with increase in milling frequency. It is possible that milling increases ions which polarize to the maximum extent causing to increase the dielectric values. Later on, milling reduced ions concentration that was obstructing the interaction between ions. High value of dielectric constant correlated with structural changes induced by milling reveals large values of dislocation density. The factors involved in 
determining high dielectric constant are not only the grain and grain boundaries but also some intrinsic factors such as chemical substitution which modify the electronic structure showing a significant role. This chemical substitution may be produced due to milling. Dielectric results are in good agreement with XRD findings. Lattice is deformed by milling.

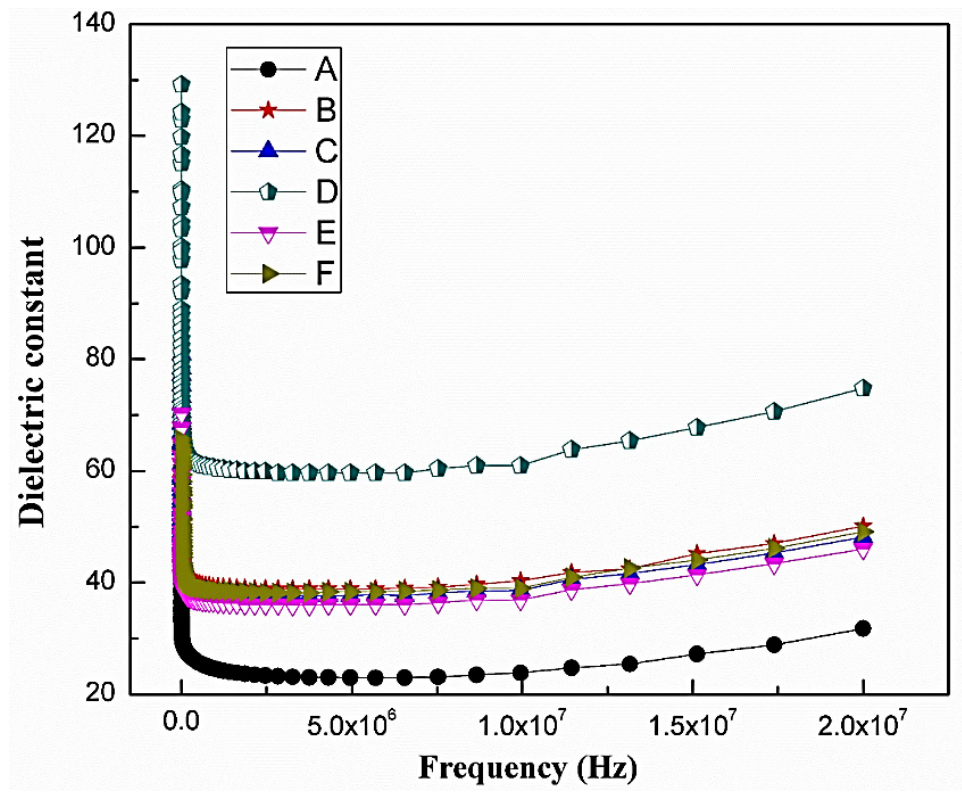

Fig. 3. Variation in dielectric constant versus frequency of samples A-F.

Fig. 5 illustrates the tangent loss ( $\tan \delta)$ as a function of frequency of samples A-F at room temperature. Variation in dielectric constant and tangent loss with frequency of applied electric field exhibits the same trends. In a low frequency regime, role of grain boundaries is dominated. Therefore, high energy is required for electrons to move from one ion to other present at different sites. As frequency is increased to the higher values, low energy is required for hopping of electrons due to low resistivity of grains resulting the tan loss become minimum. AC conductivity is plotted against frequency as shown in Fig. 6. AC conductivity is increased with an increase in frequency. In general, dielectric material does not possess any conductivity due to movements of free charges. Conductivity in dielectric material is only due to the hopping of bound charges. In hopping mechanism, charges move between bound states at different sites. This hopping mechanism speeds up at high frequency resulting in an increase in conductivity.

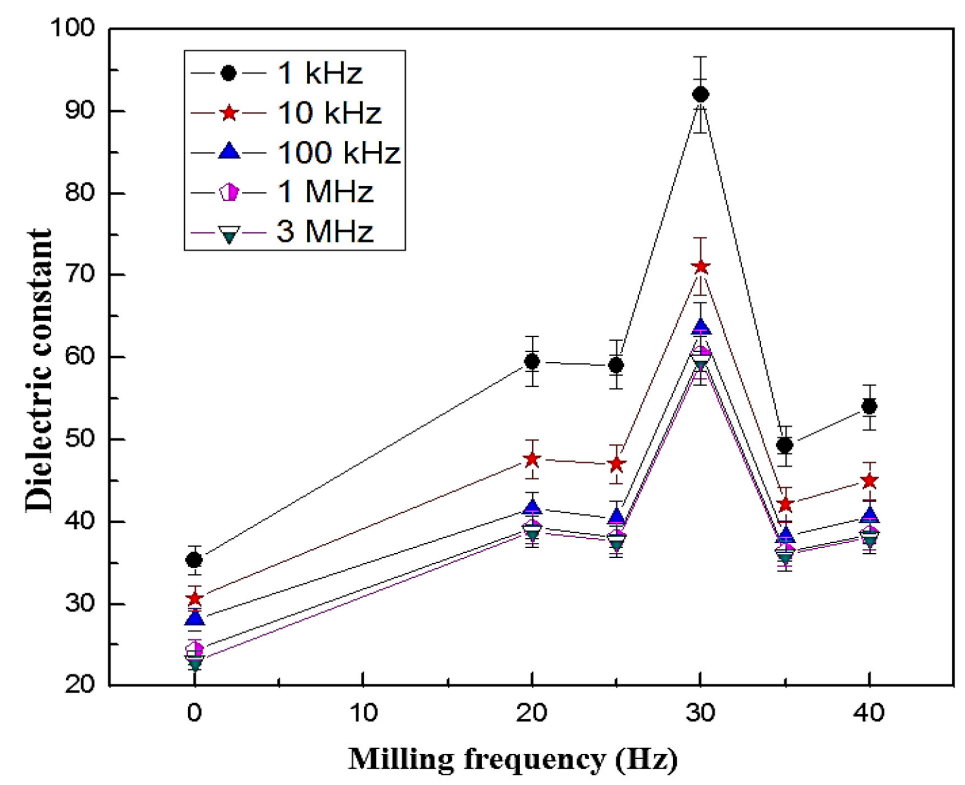

Fig. 4. Variation in dielectric constant versus milling frequency at different frequency of applied field. 


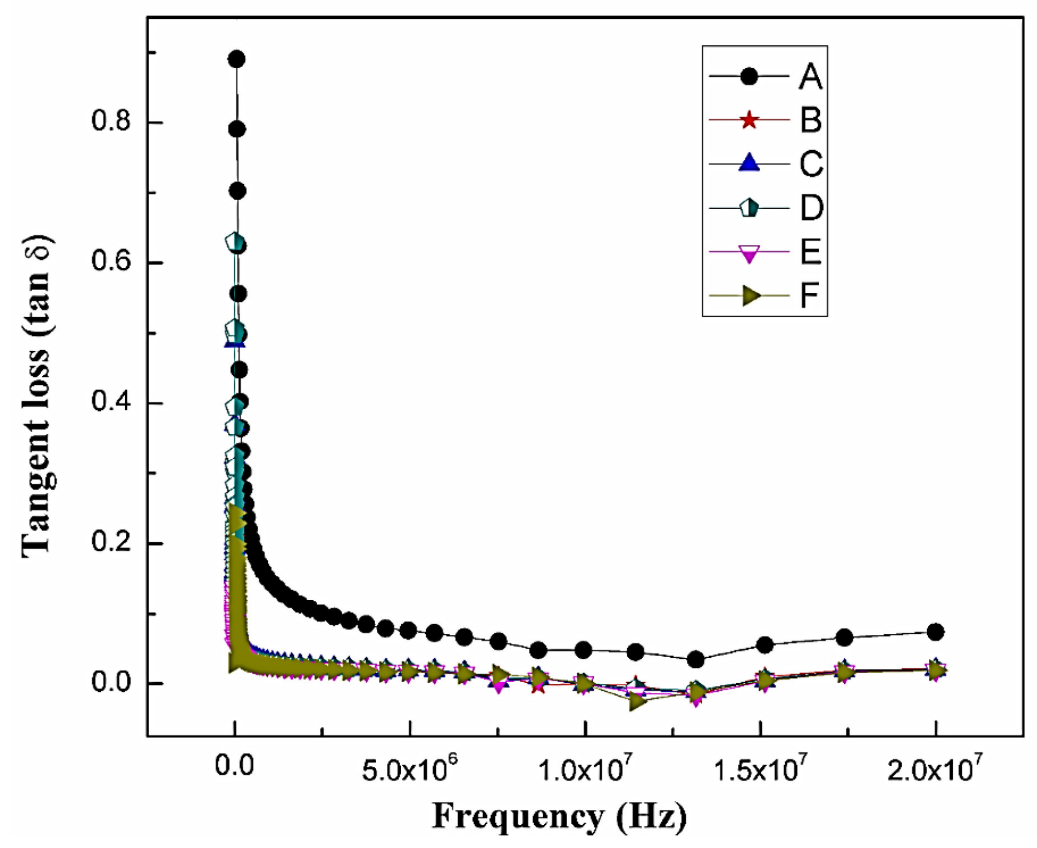

Fig. 5. Variation in tan loss versus frequency of samples A-F.

Fig.7 represents the Nyquist plots of samples A-F. Impedance spectrum can be explained by Nyquist plots. It contains different mechanisms related to grains, grain boundaries and electrode contribution. When a straight line is formed from impedance data, it indicates the insulating nature of material. Formation of semicircle points out the conducting nature of specimen having contribution of grains, grain boundaries and electrode [28]. It is found that an arc of sample D has minimum radius which shows the more conducting nature of sample as compared to others. This observation is consistent with dielectric results. However, in present study, spectrum contains a single semicircle which represents the contribution of grain interior (bulk) [29]. An equivalent circuit consisting of resistance of grains $\left(\mathrm{R}_{\mathrm{g}}\right)$, resistance of grain boundary $\left(\mathrm{R}_{\mathrm{gb}}\right)$, capacitance of grains $\left(\mathrm{C}_{\mathrm{g}}\right)$ and capacitance of grain boundary $\left(\mathrm{C}_{\mathrm{gb}}\right)$ were suggested and values of $\mathrm{R}_{\mathrm{g}}, \mathrm{R}_{\mathrm{gb}}, \mathrm{C}_{\mathrm{g}}$ and $\mathrm{C}_{\mathrm{gb}}$, were determined as listed in Table II. Samples A-F show different center of semicircles to indicate the variation in grain resistance by milling. Consequently, it confirms the non-Debye behavior of material. It is recommended that different relaxation time exist due to lattice distortion. This observation is consistent with XRD and dielectric results.

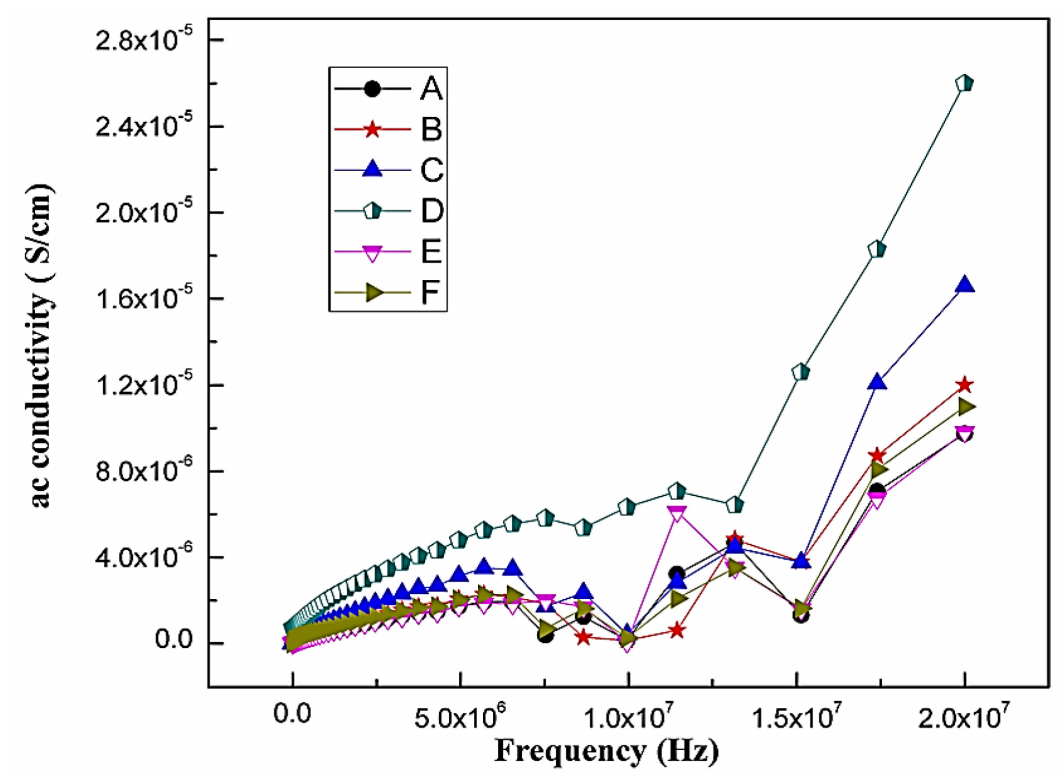

Fig. 6. Variation in ac conductivity as a function of frequency. 


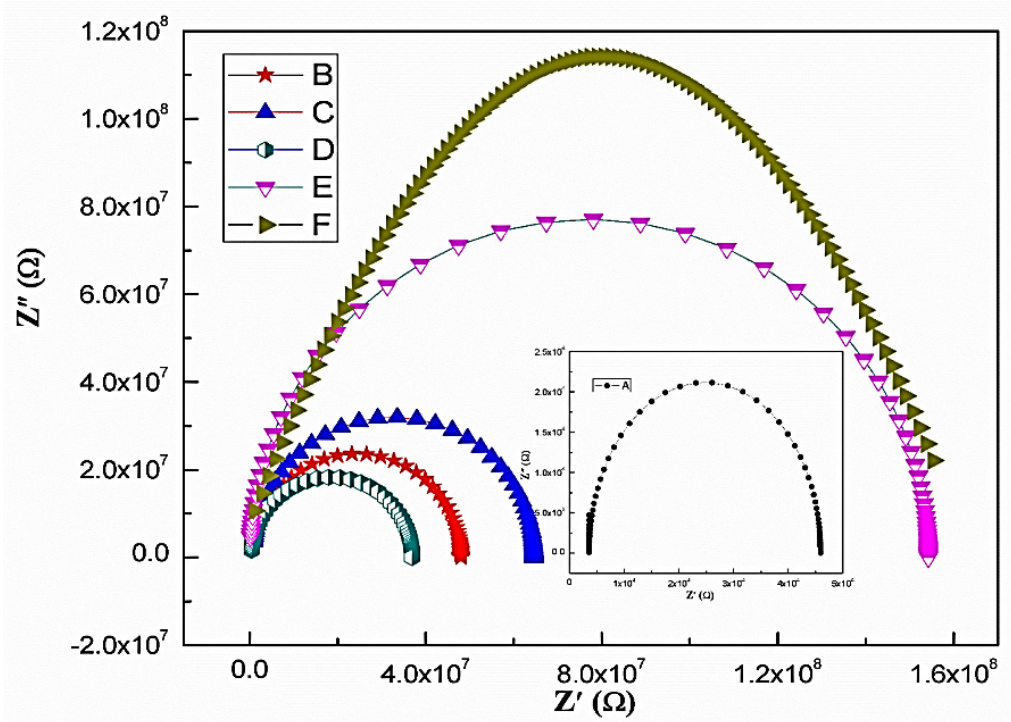

Fig. 7. Nyquist plots of samples A-F.

Table 2. Summary of electrical parameter determined from fitted model in association with experimental data.

\begin{tabular}{|c|l|l|l|l|}
\hline Sample ID & $\mathbf{R}_{\mathbf{g}}(\mathbf{o h m})$ & $\mathbf{R}_{\mathbf{g b}}(\mathbf{o h m})$ & $\mathbf{C}_{\mathbf{g}}(\mathbf{F})$ & $\mathbf{C}_{\mathbf{g b}}(\mathbf{F})$ \\
\hline A & $4.317 \times 10^{8}$ & 42409 & $1.413 \times 10^{-6}$ & $5.6917 \times 10^{-8}$ \\
\hline B & $2.532 \times 10^{15}$ & $4.713 \times 10^{7}$ & $3.953 \times 10^{-9}$ & $4.904 \times 10^{-12}$ \\
\hline C & $6.384 \times 10^{7}$ & $1.062 \times 10^{17}$ & $3.913 \times 10^{-12}$ & $5.271 \times 10^{-9}$ \\
\hline D & $7.938 \times 10^{7}$ & $1.002 \times 10^{7}$ & $8.458 \times 10^{-12}$ & 0.00441 \\
\hline E & $5.622 \times 10^{22}$ & $1.542 \times 10^{8}$ & 9037 & $1.388 \times 10^{-12}$ \\
\hline F & $9.50 \times 10^{7}$ & $2.205 \times 10^{20}$ & $3.11 \times 10^{-12}$ & 4822 \\
\hline
\end{tabular}

Fig. 8 represents a complex impedance data of sample $\mathrm{D}$ at different temperatures varying from 30 to $260{ }^{\circ} \mathrm{C}$. The values of $\mathrm{R}_{\mathrm{g}}, \mathrm{R}_{\mathrm{gb}}, \mathrm{C}_{\mathrm{g}}$ and $\mathrm{C}_{\mathrm{gb}}$ have been evaluated by fitting the suggested circuits. The specimen is more resistive at room temperature. It is observed that arc of semicircle decreases as temperature increases which indicates the bulk resistance decrease at high temperature [29]. It gives the clue that resistance of grains is the main barrier for movement of ions. Furthermore, effective concentration of acceptor and oxygen vacancy is increased with temperature which is confirmed by thermally stimulated polarization.

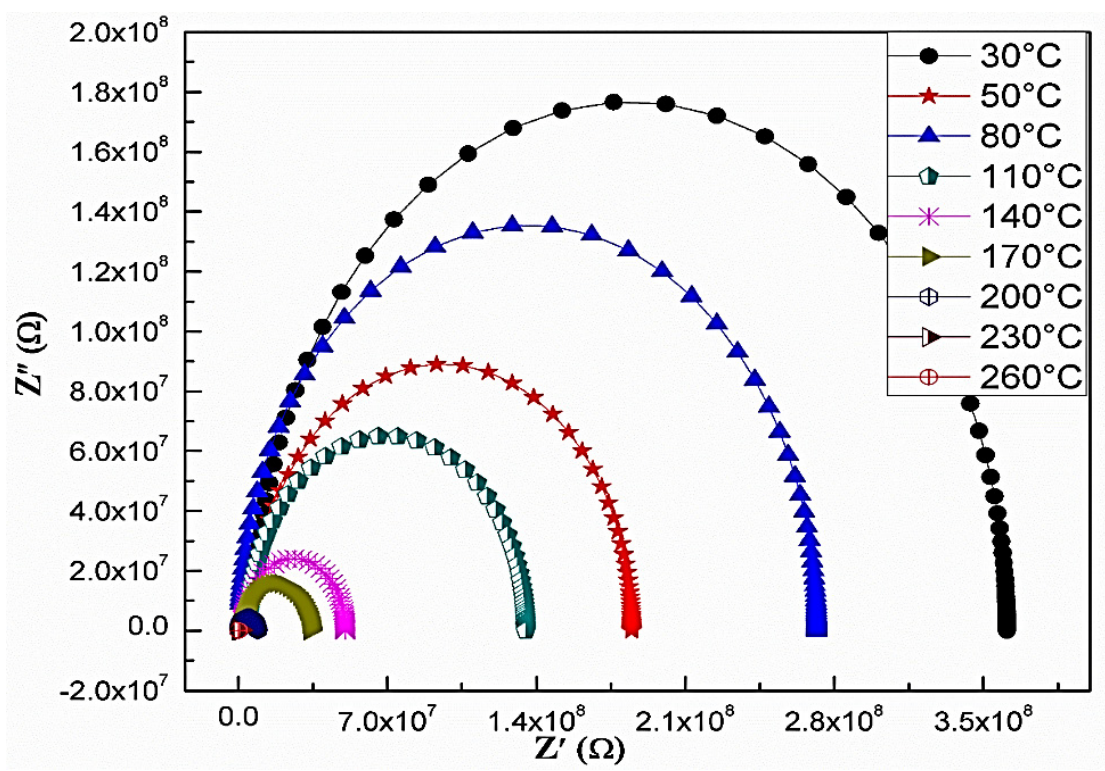

Fig. 8. Nyquist plots of sample $\mathrm{D}$ having the highest value of dielectric at different temperature. 


\section{ConclusionS}

$\mathrm{ZnAl}_{2} \mathrm{O}_{4}$ samples were prepared by solid state reaction technique based on nano ball milling. Milling frequency was changed 0 to $40 \mathrm{~Hz}$. X-ray diffraction studies revealed cubic structure. The structural parameters such as crystallite size, dislocation density, lattice constant and unit cell volume were calculated. XRD analysis explained lattice distortion due to milling. The dielectric constant, tangent loss and ac conductivity exhibited increasing behavior with increasing frequency well explained with the help of Koop's theory. Impedance spectroscopy highlighted the grain effects using equivalent circuit to describe electrical mechanism inside the material resulting in nonDebye type relaxation existing in the material. Nyquist plots at different temperature suggested that conduction mechanism in material was due to the increase in number of grains and thus the resistance.

\section{References}

[1] N. Ueda, T. Omata, N. Hikuma, K. Ueda, H. Hizoquchi, T. Hashimoto, H. Kawazoe, New oxide phase with wide band gap and high electro-conductivity, $\mathrm{MgIn}_{2} \mathrm{O}_{4}$, Appl. Phys. Lett., 61 (1992) 1954-1955.

[2] R. Pandey, J.D. Gale, S.K. Sampath, J.M. Recio, Atomistic simulation study of spinel oxides: zinc aluminate and zinc gallate, J. Am. Ceram. Soc., 82 (1999) 3337-3341.

[3] J. Wrzyszcz, M. Zawadzki, J. Trawczyński, H. Grabowska, W. Miśta, Some catalytic properties of hydrothermally synthesised zinc aluminate spinel, Appl. Catalysis. A, 210 (2001) 263-269.

[4] S. Mathur, M. Veith, M. Haas, H. Shen, N. Lecerf, V. Huch, S. Hüfner, R. Haberkorn, H.P. Beck, M. Jilavi, Single-source sol-gel synthesis of nano-crystalline $\mathrm{ZnAl}_{2} \mathrm{O}_{4}$ : structural and optical properties, J. Am. Ceram. Soc., 84 (2001) 1921-1928.

[5] Y. Yang, X.W. Sun, B.K. Tay, J.X. Wang, Z.L. Dong, H.M. Fan, Twinned $\mathrm{Zn}_{2} \mathrm{TiO}_{4}$ spinel nanowires using $\mathrm{ZnO}$ nanowires as a template, Adv. Mater., 19 (2007) 1839-1844.

[6] F. Le Pelier, P. Chaumette, J. Saussey, M.M. Bettahar, J.C. Lavalley, In-situ FT-IR spectroscopy and kinetic study of methanol synthesis from $\mathrm{CO} / \mathrm{H}_{2}$ over $\mathrm{ZnAl}_{2} \mathrm{O}_{4}$ and $\mathrm{Cu}-\mathrm{ZnAl}_{2} \mathrm{O}_{4}$ catalysts, Mol. Catal. A: Chem., 122 (1997) 131-139.

[7] L.R. Cobb, Preparation of Polymethylbenzenes, U.S. Patent 4.568.784, 1985.

[8] A. Escardino, J.L. Amorós, A. Gozalbo, M.J. Orts, A. Moreno, Gahnite devitrification in ceramic frits: mechanism and process kinetics. Journal of the American Ceramic Society, J. Am. Ceram. Soc., 83 (2000) 2938-2944.

[9] K. Kumar, K. Ramamoorthy, P.M. Koinkar, R. Chandramohan, K. Sankaranarayanan, A novel in situ synthesis and growth of $\mathrm{ZnAl}_{2} \mathrm{O}_{4}$ thin films. J. Cryst. Grow. 289 (2006) 405-407.

[10] Y. Wang, K. Wu, As a Whole: Crystalline zinc aluminate nanotube array-nanonet, J. Am. Chem. Soc., 127 (2005) 9686-9687.

[11] A. Thomas, B. Premlal, M. Eswaramoorthy, Synthesis of mesoporous $\mathrm{Zn}-\mathrm{Al}$ spinel oxide nanorods with membrane like morphology, Mater. Res. Bull., 41 (2006) 1008-1014.

[12] R. Mouazer, M. Persin, M. Cretin, A. Larbot A. Preparation and characterization of NASICON-ZnAl $\mathrm{O}_{4}$-based ultrafiltration membranes, Colloids and Surfaces A: Physicochem. Eng. Aspects., 244 (2004) 95-104.

[13] G. Aguilar-Rfos, M. Valenzuela, P. Salas, H. Armendfiriz, P. Bosch, G. Del Toro, R. Silva, V. Bertfn, S. Castillo, A. Ramfrez-Solfs, I. Schifter, Hydrogen interactions and catalytic properties of platinum-tin supported on zinc aluminate, Appl. Catal. A-Gen., 127 (1995) 65-75. 
[14] E. Martinez-Sanchez, M. Garcia-Hipolito, J. Guzman, F. Ramos-Brito, J. Santoyo- Salazar, R. Martinez Martinez, O. Alvarez-Fregoso, M.I. Ramos-Cortes, J.J. Mendez-Delgado, C. Falcony, Cathodoluminescent characteristics of $\mathrm{Sm}$ doped $\mathrm{ZnAl}_{2} \mathrm{O}_{4}$ nanostructured powders, Phys. Stat. Sol., (a) 202 (2005) 102-107.

[15] Y. Wu, J. Du, K.L. Choy, L.L. Hench, J. Guo, Formation of interconnected microstructural $\mathrm{ZnAl}_{2} \mathrm{O}_{4}$ films prepared by sol-gel method, Thin Solid Fil., 472 (2005) 150- 156.

[16] A. R. Phani, M. Passacantando, S. Santucci, Synthesis and characterization of zinc aluminum oxide thin films by sol-gel technique, Mater. Chem. Phys., 68 (2001) 66-71.

[17] Z. Chen, E. Shi, Y. Zheng, W. Li, N. Wu, W. Zhong, W. Synthesis of monodispersed $\mathrm{ZnAl}_{2} \mathrm{O}_{4}$ powders under hydrothermal conditions, Mater. Lett., 56 (2002) 601- 605.

[18] M. Zawadzki, Synthesis of nanosized and microporous zinc aluminate spinel by microwave assisted hydrothermal method (microwave-hydrothermal synthesis of $\mathrm{ZnAl}_{2} \mathrm{O}_{4}$ ), Sol. Stat. Sci,. 8 (2006) 14-18.

[19] H. Noor, H. Yousaf, M. A. Naseer, N. Iqbal, N. Tariq, S. Riaz and S. Naseem, Ball milling effect on structural, optical and dielectric properties of $\mathrm{Y}_{2} \mathrm{O}_{3}$, Proceedings of the International Conference on Sustainable Materials Science and Technology, 15-17 July 2015, Paris, France.

[20] A.F. Osorio, D.H. Mendoza, E.P.Villanueva, Synthesis of nano-crystalline $\left(\mathrm{Zn}_{1-\mathrm{x}} \mathrm{Co}_{\mathrm{x}}\right) \mathrm{Al}_{2} \mathrm{O}_{3}$ solid solution: structural and optical properties, NSTI-Nanotech, 1 (2010) 448-451.

[21] E.M.A. Jamal, D.S. Kumar, M.R. Anantharaman, On structural, optical and dielectric properties of zinc aluminate nanoparticles, Bull. Mater. Sci., 34 (2011) 251-259.

[22] S. Talam, S.R. Karumuri, N. Gunnam, Synthesis, Characterization and spectroscopic properties of $\mathrm{ZnO}$ nanoparticles, ISRN Nanotechnol., 2012 (2012) 1-7.

[23] V. Priiyawong, V. Thongpool, P. Asanithi, P. Limsuwan, Preparation and characterization of alumina nanoparticles in deionized water using laser ablation technique, J. Nanomater., 2012 (2012) $1-6$.

[24] B.D. Culity, Elements of x-ray diffraction, Addison-Wesley Publishing Company, 1956.

[25] S. Neogi, U. Chowdhury, A.K. Chakraborty, J. Ghosh, Effect of mechanical milling on the structural and dielectric properties of $\mathrm{BaTiO}_{3}$ powders, Micro \& Nano Lett., 10 (2015) 109-114.

[26] S. S. Kumbhar, M. A. Mahadik, P. K. Chougule, V. S. Mohite, Y. M. Hunge, K. Y. Rajpure, A. V. Moholkar, C. H. Bhosale, Structural and electrical properties of barium titanate $\left(\mathrm{BaTiO}_{3}\right)$ thin films obtained by spray pyrolysis method, Mater. Sci.-Poland., 33 (2015) 852-861.

[27] K. W. Wagner, Zur theorie der unvollkommenen dielektrika, Annalen der Physik., 345 (1993), 817-855.

[28] E. Barsoukov, J. R. Macdonald, Theory, experiment and application, John Wiley \& sons, Inc, 2005.

[29] Y. D. Kolekar, L. J. Sanchez, C. V. Ramana, Dielectric relaxations and alternating current conductivity in manganese substituted cobalt ferrite, J. Appl. Phys., 115 (2014) 144106-11. 